\title{
A case of a rectal stricture related to ischemic proctitis following rupture of an aortic aneurysm
}

\section{(ㄷ)(잉}

Authors

Tomoya lida ${ }^{1}$, Yosuke Ohkubo ${ }^{1}$, Toshiyuki Kubo ${ }^{1}$, Kentaro Yamashita ${ }^{1}$, Kei Onodera ${ }^{1}$, Eiichiro Yamamoto ${ }^{1}$, Katsuhiko Nosho', Toshiro Ito ${ }^{2}$, Hiroo Yamano ${ }^{1}$, Hiroshi Nakase ${ }^{1}$

Institutions

1 Department of Gastroenterology and Hepatology, Sapporo Medical University School of Medicine. Hokkaido, Japan

2 Department of Cardiovascular Surgery, Sapporo Medical University School of Medicine, Hokkaido, Japan

submitted 19.1.2017

accepted after revision 27.6.2017

Bibliography

DOI https://doi.org/10.1055/s-0043-117946 |

Endoscopy International Open 2018; 06: E186-E189

(c) Georg Thieme Verlag KG Stuttgart · New York ISSN 2364-3722
Corresponding author

Hiroshi Nakase, MD, PhD, Department of Gastroenterology and Hepatology, Sapporo Medical University School of

Medicine, Minami 1-jo Nishi 16-chome, Chuo-ku, Sapporo, Hokkaido, 060-8556, Japan

Fax: +81-11-611-2282

hiropynakase@gmail.com

\section{ABSTRACT}

Background and study aims Ischemic proctitis is a rare disease and comprises $2 \%$ to $5 \%$ of cases of ischemic colitis, because the rectum has abundant blood supply and rich collaterals. Herein, we report a case of a 73-year-old male patient with a pronounced rectal stricture caused by ischemic proctitis resulting from an abdominal aortic rupture and treated by endoscopic balloon dilation therapy. To date, only 3 cases of rectal stricture related to ischemic proctitis including our case have been reported, and this is the first case of rectal stricture related to ischemic proctitis, which was successfully treated by endoscopic balloon dilation.

\section{Introduction}

Ischemic colitis (IC) is the most common form of intestinal ischemic disease, which is estimated to account for approximately 3 in 1000 of all admissions to tertiary hospitals [1]. In a prospective study conducted in 24 Spanish hospitals, IC was the reason for 1.28 per 1000 hospital admissions [2]. Initially, Marston et al. categorized IC into the 3 forms of transient, stricturing, and gangrenous IC [3]. Approximately 10 years later, he revised the narrow definition of IC to include only the transient and stricturing types [4], a definition that is commonly used. Most cases are transient and not accompanied by morphological change. Generally, the blood vessels in the rectal region are abundant and acute spontaneous ischemia of the rectum is not likely to occur [5]. However, several cases exhibiting rectal ischemia particularly after cardiovascular surgery were reported, and some of them exhibited stricture formation.

We herein report a rare case exhibiting rectal stricture related to ischemic proctitis (IP) caused by an abdominal aortic rupture and treated by endoscopic dilation.

\section{Case Report}

The patient was a 73-year-old man. He was on medication for angina and hypertension, but had no history of continuous use of nonsteroidal anti-inflammatory drugs (NSAIDs) or digestive system disorders. In addition, he had a 50-year history of smoking. He underwent emergency surgery because of a ruptured abdominal aortic aneurysm. Pronounced intestinal edema associated with bowel ischemia was observed. Therefore, abdominal closure was performed on the second post-surgical day after the surgeon confirmed the improvement of intestinal edema without necrosis. The patient's clinical course after the second post-surgery day was fine. He was discharged from our hospital a month after surgery.

Because the patient complained of sustained diarrhea with slight hematochezia 15 months after surgery, enhanced computed tomography (CT) was performed. CT showed slight thickening of the rectal wall, but no lymph node enlargement or signs of distal metastasis. Colonoscopy showed a severe stricture in the lower rectum. Ileostomy was performed at the 

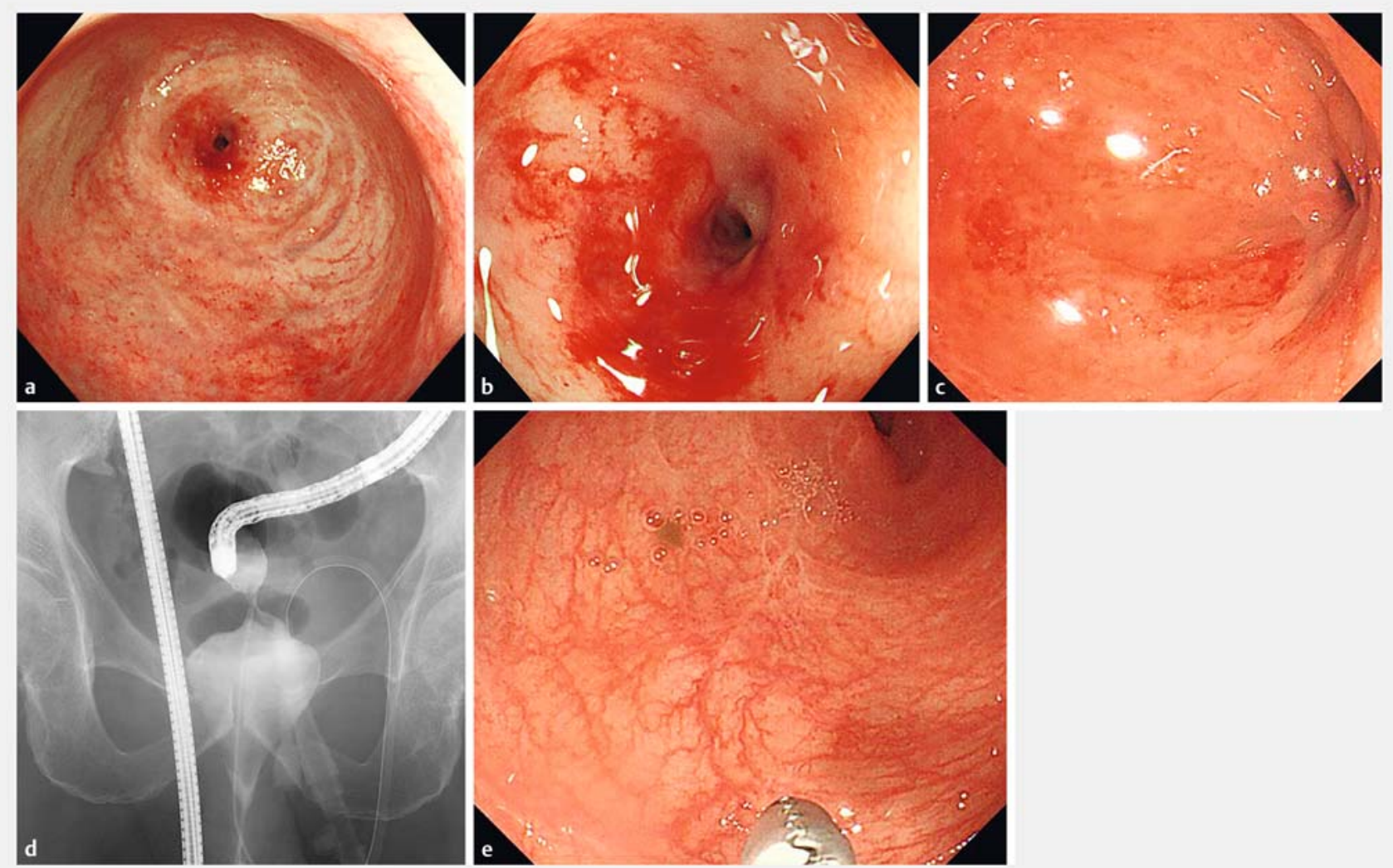

- Fig. 1 a, b Colonoscopy (CS) from the anus revealed a pinhole-shaped stricture with a smooth circumference in the lower rectum. c, d Furthermore, CS from the ileostomy revealed the same stricture with a length of approximately $2 \mathrm{~cm}$. e Ulcer scars were observed at the oral side of stenosis. The surface structure was endoscopically normal, and histological examinations of biopsy specimen showed no abnormality including malignancy. Therefore, we diagnosed a rectal stricture caused by impairment of vascular flow associated with rupture of aortic aneurysm.

previous hospital because the patient developed sub-ileus symptoms, such as vomiting and abdominal pain After that, he was transferred to our hospital for detailed investigation of the rectal stricture. Colonoscopy from the anus revealed a pinholeshaped stricture with a smooth circumference in the lower rectum ( $\triangleright$ Fig.1a, $\triangleright$ Fig.1b). Furthermore, colonoscopy from the ileostomy revealed the same stricture with a length of approximately $2 \mathrm{~cm}$ ( $>$ Fig. 1c, > Fig. 1d). Ulcer scars were observed on the oral side of the stenosis ( $\triangleright$ Fig. 1e). The surface structure was endoscopically normal, and histological examinations of biopsy specimen showed no abnormalities, including malignancy. Therefore, this patient was diagnosed with a rectal stricture caused by impairment of vascular flow associated with rupture of aortic aneurysm. Endoscopic dilation therapy with CRE lower intestinal balloon dilation catheter (Boston Scientific, Tokyo, Japan) was uneventfully performed for rectal stricture (using balloons of sizes 6-9, 9-12, and $12-15 \mathrm{~mm}$ for 3 minutes $\times 3$ sessions every other week; $>$ Fig. 2 a, $>$ Fig. 2 b). Corticosteroid injection was not added simultaneously. Ileostomy closure was performed after the patient received several additional endoscopic dilatation therapies and functional exploration of the rectum.

\section{Discussion}

In this report, we described the case of a patient with a pronounced rectal stricture caused by IP resulting from an abdominal aortic rupture and treated by endoscopic balloon dilation therapy. Of note, this is the first case of rectal stricture with IP that was successfully treated by endoscopic balloon dilation therapy. IC occurs more commonly in women, and risk increases with advancing age. Patients older than age 60 account for as many as $90 \%$ of cases of ischemic colitis. The dominant location of IC is commonly the left side of the colon. Presenting symptoms include abdominal pain, bowel urgency, and passage of bloody diarrhea, however, nearly one-half of patients do not present with this classic triad of symptoms [6].

IP is a rare disease and comprises $2 \%$ to $5 \%$ of cases of IC because the rectum has an abundant blood supply and rich collaterals [5]. It usually occurs in elderly patients with atherosclerotic disease and cardiac risk factors. It appears as a result of sudden acute compromise in blood flow in patients with inadequate collateral circulation around the rectum.

Abdominal aortic aneurysm surgery, vascular embolization surgery, systemic lupus erythematosus, anaphylactic shock, and use of NSAID suppositories and phosphate enemas are fac- 


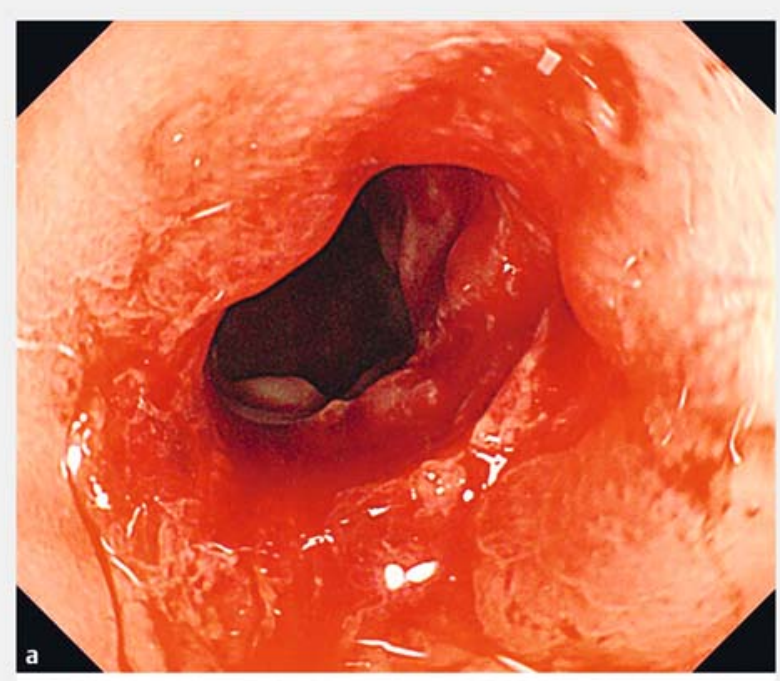

b

Fig. 2 Endoscopic dilation therapy with CRE lower intestinal balIoon dilation catheter (Boston Scientific, Tokyo, Japan) was uneventfully performed for rectal stricture (using balloons of sizes $6-9,9-12$, and $12-15 \mathrm{~mm}$ for 3 minutes $\times 3$ sessions every other week).

tors related to IP. Most patients present with diarrhea, hematochezia, both abdominal and pelvic pain, and distention. Fever, and tachycardia with hypotension often are present. Nelson et al reported that loss of anal tone is an early sign of acute rectal ischemia [5]. Conservative management is enough in early cases or in cases with superficial ischemia, while emergency surgery is required in cases of frank gangrene of the rectum.
Sharif et al reported that mortality was $40 \%$ in case of transmural necrosis of the rectal wall [7].

In the current case, IP caused by an abdominal aortic rupture is considered to have resulted in the rectal stricture. Previous reports indicate that abdominal aortic rupture contributes to rectal ischemia, which conceivably can result from a number of circumstances. The first theory is that inadequate blood flow results from the inferior mesenteric arterial system when the internal iliac arterial system becomes intertwined because of a dissecting aortic aneurysm. The second theory is that inadequate blood flow results from changes in blood flow after elective surgery for an abdominal aortic aneurysm. The third theory is that, as observed in our patient, blood flow to the lower body is sacrificed to maintain blood flow to the heart and head while the patient is in shock and emergency surgery is being conducted owing to a ruptured aneurysm. A recent meta-analysis demonstrated the prevalence rate of $0.4 \%$ to $17.2 \%$ for IC perioperative to abdominal aortic aneurysm (AAA) surgery.

Emergency repair of AAA also reportedly is associated with a relative risk of 7.36 compared with elective repair ( $95 \%$ confidence interval $(\mathrm{Cl}) 3.08$ to $17.58, P<0.001)$. Furthermore, endovascular aneurysm repair showed a relative risk of 0.22 (95\% $\mathrm{Cl} 0.12$ to $0.39, P<0.001)$ compared with open repair surgery [8].

In the current case, an elderly patient with a background of arteriosclerotic disease, including angina and hypertension, had been in shock during an abdominal aortic aneurysm rupture. In addition to his shocked condition, maintenance of blood flow to his upper body using intra-aortic balloon pumping miay have resulted in insufficient blood flow to the rectum.

To date, only 2 cases of rectal stricture related to IP have been reported ( $\vee$ Table 1 ). Curr et al. reported a case wherein a stricture occurred in the lower rectum because of ectopic pregnancy [9]. In addition, Lane et al. reported a case wherein a stricture occurred in the middle rectum and was associated with an abdominal aortic rupture [10]. Although the initial symptom in these 2 cases was incontinence, our patient complained of sub-ileus symptoms with hematochezia. Endoscopic balloon dilation therapy was attempted in both cases, but it was not successful. Both patients finally required colostomy, while our patient did not because his IP-related rectal stricture was successfully treated by endoscopic balloon dilation.

\section{Conclusion}

We herein reported a patient with rectal stricture caused by IP resulting from an abdominal aortic rupture. Despite very low frequency, we should keep in mind the possibility that clinically ischemia occurs not only in the left-side colon but also in the rectum. 
- Table 1 Three cases that revealed rectal stricture related to ischemic proctitis.

\begin{tabular}{|c|c|c|c|c|c|c|c|c|c|c|}
\hline $\begin{array}{l}\text { Author/ } \\
\text { reference }\end{array}$ & Year & $\begin{array}{l}\text { Age } \\
\text { Sex }\end{array}$ & Smoking & $\begin{array}{l}\text { Underlying } \\
\text { disease }\end{array}$ & Onset & Operation & $\begin{array}{l}\text { Initial } \\
\text { symptom }\end{array}$ & $\begin{array}{l}\text { Stricture } \\
\text { location }\end{array}$ & $\begin{array}{l}\text { Time to } \\
\text { stricture }\end{array}$ & $\begin{array}{l}\text { Treat- } \\
\text { ment }\end{array}$ \\
\hline \multirow[t]{2}{*}{$\begin{array}{l}\text { Curr } \\
\text { et al. [9] }\end{array}$} & 1967 & 40 & ND & - & $\begin{array}{l}\text { Rupture of } \\
\text { ectopic } \\
\text { pregnancy }\end{array}$ & Laparotomy, & $\begin{array}{l}\text { Inconti- } \\
\text { nence }\end{array}$ & $\begin{array}{l}\text { Lower } \\
\text { rectum }\end{array}$ & $\begin{array}{l}18 \\
\text { months }\end{array}$ & $\begin{array}{l}\text { Endo- } \\
\text { scopic } \\
\text { dilation }\end{array}$ \\
\hline & & $\mathrm{F}$ & & & & $\begin{array}{l}\text { Removed } \\
\text { left tube and } \\
\text { ovary }\end{array}$ & & & & $\begin{array}{l}\rightarrow \text { Co- } \\
\text { lostomy }\end{array}$ \\
\hline \multirow[t]{2}{*}{$\begin{array}{l}\text { Lane } \\
\text { et al. [10] }\end{array}$} & 2000 & 61 & + & - & $\begin{array}{l}\text { Rupture of } \\
\text { aortic } \\
\text { aneurysm }\end{array}$ & Laparotomy, & $\begin{array}{l}\text { Inconti- } \\
\text { nence }\end{array}$ & $\begin{array}{l}\text { Middle } \\
\text { rectum }\end{array}$ & $\begin{array}{l}3.5 \\
\text { months }\end{array}$ & $\begin{array}{l}\text { Endo- } \\
\text { scopic } \\
\text { dilation }\end{array}$ \\
\hline & & M & & & & $\begin{array}{l}\text { Inserted } \\
\text { tube graft }\end{array}$ & & & & $\begin{array}{l}\rightarrow \text { Co- } \\
\text { lostomy }\end{array}$ \\
\hline \multirow[t]{2}{*}{ Our case } & 2017 & 73 & + & Hypertension & $\begin{array}{l}\text { Rupture of } \\
\text { aortic } \\
\text { aneurysm }\end{array}$ & Laparotomy, & $\begin{array}{l}\text { Hemato- } \\
\text { chezia }\end{array}$ & $\begin{array}{l}\text { Lower } \\
\text { rectum }\end{array}$ & $\begin{array}{l}15 \\
\text { months }\end{array}$ & $\begin{array}{l}\text { Endo- } \\
\text { scopic } \\
\text { dilation }\end{array}$ \\
\hline & & M & & Angina & & $\begin{array}{l}\text { Inserted } \\
\text { tube graft }\end{array}$ & Sub-ileus & & & \\
\hline
\end{tabular}

\section{Competing interests}

None

\section{References}

[1] Brandt LJ, Boley SJ. AGA technical review on intestinal ischemia. American Gastrointestinal Association. Gastroenterology 2000; 118: 954-996

[2] Montoro MA, Brandt LJ, Santolaria S et al. Clinical patterns and outcomes of ischaemic colitis: results of the Working Group for the Study of Ischaemic Colitis in Spain (CIE study). Scand J Gastroenterol 2011; 46: $236-246$

[3] Marston A, Pheilis MT, Thomas ML et al. Ischemic colitis. Gut 1966; 7: $1-15$
[4] Marston A. Intestinal ischemia. First edition. London: Edward Arnold; 1977: $143-175$

[5] Nelson RL, Schuler J]. Ischemic proctitis. Surg Gynecol Obstet 1982; 154: $22-27$

[6] Flynn AD, Valentine JF. Update on the Diagnosis and Management of Colon Ischemia. Curr Treat Options Gastroenterol 2016; 14: 128-139

[7] Sharif S, Hyser M. Ischemic proctitis: case series and literature review. Am Surg 2006; 72: 1241 - 1247

[8] Lee M], Daniels SL, Drake TM et al. Risk factors for ischaemic colitis after surgery for abdominal aortic aneurysm: a systematic review and observational meta-analysis. Int ] Colorectal Dis 2016; 31: 1273 1281

[9] Lane TM, Bentley PG. Rectal strictures following abdominal aortic aneurysm surgery. Ann R Coll Surg Engl 2000; 82: 421-423

[10] Curr JF. Rectal stricture due to ischaemia following ruptured ectopic gestation. Gut 1967; 8: 178-179 